\title{
Cause and Influence of Mass Concrete Crack
}

\author{
Zhineng Tong \\ Jiangxi science and technology Normal University
}

\begin{abstract}
In this paper, the influence of crack of the big physical volume concrete, types of cracks, cracks reasons were comprehensive analysis, expounds the key elements of large volume concrete configuration, construction and maintenance and other aspects of the, proposed to reduce and control of crack of the big physical volume concrete technical requirements, for the same project provides theoretical reference.
\end{abstract}

Keywords- Mass concrete;Crack;Influence factors;Control

\section{PREFACE}

In our country the construction of large volume concrete norms "GB50496-2009 provisions: concrete structure entity minimum geometry of not less than $1 \mathrm{~m}$ of large volume concrete, or is expected to will for concrete cementitious material hydration caused by temperature change and shrinkage caused harmful cracks of concrete, known as the big volume concrete.

In modern times, the construction of large volume concrete is often involved, such as high - level building foundation, large equipment foundation, water conservancy dam, etc.. Its main feature is the size of large, the general entity minimum size is greater than or equal to $1 \mathrm{~m}$. its surface coefficient is small, cement hydration heat release more concentrated, internal heating up faster. When temperature difference between inside and outside of concrete is large, temperature cracks of concrete will be caused, which will affect the safety and normal use of structure.. So we must analyze it from the fundamental, to ensure the quality of the construction.

\section{THE INFLUENCE OF MASS CONCRETE CRACK}

There are kinds of cracks in the mass concrete, which are different depth, and are divided into three kinds of cracks, deep cracks and surface cracks.. Through the cracks, the crack is the crack of the concrete surface, and the crack is formed through the crack.. It cut off the structure section, may undermine the integrity and stability of the structure, its harm is more serious; and deep cracks in partially cut section structure, there are certain dangers; surface crack damage is generally small.

But the crack is not absolutely affect the structural safety, it has a maximum allowable value. In normal indoor environment for general component maximum crack width is less than or equal to $0.3 \mathrm{~mm}$ in the outdoor or indoor high humidity environment of the component of the maximum crack width is less than or equal to $0.2 \mathrm{~mm}$.

For underground or semi underground structures, the cracks of concrete mainly affect its waterproof performance. Generally, when the crack width is $0.1 \sim 0.2 \mathrm{~mm}$, although there is slight seepage in the early stage, the crack can be self-healing after a period of time.. If more than $0.2 \sim 0.3 \mathrm{~mm}$, the leakage of water will increase rapidly with the increase of crack width. Therefore, in the underground engineering should try to avoid more than $0.3 \mathrm{~mm}$ throughout the crack of the whole section. Such cracks will greatly affect the use of the structure, chemical grouting must be carried out treatment.

Stage of construction of large volume concrete temperature crack, on the one hand is the internal factors of concrete, concrete temperature difference between inside and outside influence; on the other hand is the external factors of concrete, the structure of external constraints and concrete each particle constraints to prevent shrinkage deformation of concrete, concrete compressive strength, tension small. When the temperature stress once more than the tensile strength of the concrete can bear, the cracks will appear. The width of this crack can not affect the strength of the structure, but it has an effect on the durability of the structure, so it must be paid attention and controlled.

\section{MASS CONCRETE CRACK TYPE}

Causes of cracks in the points into two categories: structure type crack is caused by the external load, including in the calculation of the conventional structure of the main stress and other structural stress caused by the stress cracks. Two is the material type crack, is by the non bearing the distortion change, is mainly by the temperature stress and the concrete contraction cause. The main discussion of material type cracks.

\section{A. Temperature crack}

The temperature cracks are caused mainly by temperature difference between inside and outside of concrete.. The temperature difference between inside and outside can be divided into the following three types: concrete pouring stage, produce a lot of heat of hydration, the concrete is a poor conductor of heat, hydration heat accumulation easy to distribute in the concrete, the concrete internal temperature rise, and the concrete surface temperature for the outdoor environment temperature, which formed the concrete temperature difference, temperature difference inside and outside of the concrete in the initial tensile stress occurs when exceeding the compressive strength of concrete, will lead to concrete cracks; in addition, the removal of before and after, the surface temperature decreases quickly, causing sudden temperature drop, will lead to cracks; when the concrete reached the highest temperature, lowest temperature or using heat gradually dissipate the temperature is reached, the difference of temperature and the highest temperature is the temperature difference; the three temperature will produce temperature crack. In the three kinds of temperature difference, the inner temperature of the water temperature caused by the hydration heat. 


\section{B. Shrinkage cracks}

There are many kinds of shrinkage, including dry shrinkage, plastic shrinkage, autogenous shrinkage, carbonation shrinkage, etc.. Here mainly refers to dry shrinkage and plastic shrinkage.

\section{Plastic shrinkage crack}

In the cement activity, the concrete temperature is higher, or in the water ash under the condition of the low can aggravate the crack. Because then significantly reduced the bleeding of concrete, surface evaporation of water can be added in time, then concrete is still in its plastic state, slightly by a little tension, concrete surface will appear uneven distribution of cracks, cracks, a further increase in the evaporation of water from the body of concrete, and cracks further expand.

\section{THE MAIN CAUSE OF CONCRETE CRACK}

\section{A. Cement hydration heat}

In the process of hydration, the amount of cement is a major source of internal heat for mass concrete.. Because of the large volume concrete section thickness, hydration heat accumulation in the interior of the structure is not easy to be lost, so that the temperature inside the concrete. The highest temperature inside the concrete, most of the $3 \sim 5 \mathrm{D}$ occurred after pouring, when the internal temperature difference between the concrete and the surface, will produce temperature and temperature deformation. The temperature stress and temperature difference, the temperature difference, the temperature stress is also greater. When the tensile strength of the concrete is not enough to resist the temperature stress, the temperature crack will begin to produce.. This is the main reason for the crack of mass concrete.

\section{B. Restriction condition}

The large volume of reinforced concrete and foundation pouring together, when the early temperature rise when the expansion deformation caused by the lower foundation and the formation of the pressure stress. Because of the small elastic modulus of concrete, creep and stress relaxation, the concrete and foundation are not strong, so the stress is small.. But when the temperature drops, the tensile stress, if the tensile strength of the concrete, the concrete will appear the vertical crack.

\section{Outside temperature change}

During the construction of mass concrete, the change of outside air temperature has a great influence on the cracking of large volume concrete.. The internal temperature of concrete is the superposition of the three of the temperature, the adiabatic temperature of cement hydration heat, and the temperature of the concrete.. The higher the outside temperature, the higher the concrete pouring temperature. The temperature drop, especially the slump, greatly increases the temperature gradient between outer concrete and concrete, resulting in temperature difference stress, causing the large volume concrete cracks. Therefore, the control of concrete surface temperature and temperature difference between the outside air temperature, but also to prevent the important part of crack.

\section{Shrinkage and deformation of concrete}

Concrete mixing water, only about $20 \%$ of the water is required for the hydration of cement, the remaining $80 \%$ will evaporate. Evaporation of excess moisture in concrete is one of the main reasons causing shrinkage of concrete volume.. This shrinkage deformation is not affected by the constraint conditions, if there is a restraint, it will produce shrinkage stress and cracks.

Concrete shrinkage, mainly cement varieties, concrete mix, admixture and admixture of varieties and construction process (especially curing conditions), etc.

\section{PREPARATION METHOD OF MASS CONCRETE}

The raw materials of large volume concrete should pay attention to the following points: Should apply the continuous gradation of coarse aggregate, fine aggregate should be used in the sand; admixture should adopt the retarder, water reducing agent; admixtures should be using fly ash, slag powder; large volume concrete in concrete strength and slump requirements under the premise to ensure should be improve the blending material and aggregate content, in order to reduce the cement content in concrete unilateral; cement should try to use low heat of hydration, the setting time of cement, give priority to the use of moderate heat Portland cement and Portland slag cement, dam cement, slag Portland cement and Portland fly-ash cement, volcanic ash matter such as Portland cement.

However, the hydration of the slag cement with low hydration heat is greater than that of other cement, and there is a lot of water on the surface of the pouring layer.. This bleeding phenomenon, not only affects the speed of construction, at the same time, the impact of construction quality. Because of the precipitation of water collected in on casting surface layer, so that the concrete water cement ratio change, and in the drainage and take away the some of the mortar, thus forming the layer containing water interlayer, destroy the bond stress of the concrete and holistic. Bleeding of concrete size and amount of water, with a great amount of water, bleeding; and and temperature on high and low, complete separation of water decreased with the increase of temperature. In addition, it also with the composition and fineness of cement. So in the selection of slag cement should try to choose a variety of bleeding, and should be in the concrete incorporation superplasticizer, to reduce the amount of water used. In the construction, the water or dry concrete can be discharged in a timely manner, and the concrete is poured out of the water, and the vibration of the vibrator is used to continue pouring a layer of concrete.

\section{POURING OF MASS CONCRETE}

Large volume concrete pouring scheme, besides should meet every concrete before the initial setting is on a new layer of concrete cover and ramming completely, buried pipeline and the anchor bolt design, concrete supply and hydration heat due to the influence of considering structure size, reinforcement spacing, pre, the commonly used method is the following:

\section{A. Overall stratification}

That is, after the first full pouring of all the pouring, and then turn back pouring second, this time should make 
the first concrete is not initially set, so that the layer by layer continuous casting, until the completion of. It is suitable for the planar size of the structure to be suitable for the construction of the structure.. When necessary, it can be divided into two segments, from the middle to the ends or from both ends to the middle at the same time pouring.

\section{B. Segmentation}

Concrete pouring, the first from the bottom, pouring to a certain distance after pouring second layers, so in turn forward pouring other layers. Due to the many layers, so after concreting, the end on the first layer of concrete is not initial setting and from the second paragraph in turn poured in layers. This scheme is suitable for the supply of concrete within the time of the unit, as the first program as concentrated. This scheme is suitable for engineering structures that are not large, area or length of the structure thickness.

\section{Inclined plane delamination}

The slope gradient is not more than $1 / 3$, and the length of the structure is 3 times more than the thickness of the structure.. Concrete from the bottom of the pouring layer, gradually move.

\section{CURING OF MASS CONCRETE}

The large volume of concrete curing is mainly to maintain proper temperature and humidity conditions, not only to meet the needs of increasing intensity, should also by artificial temperature control, to prevent the crack of concrete caused by temperature deformation. Temperature control is the concrete pouring temperature and concrete internal temperature of the highest man-made control.

Generally, there are two methods for large volume concrete curing and temperature control: A is cooling method, namely after concrete pouring molding, cooling by circulating cooling water, from the internal structure of the temperature control; another is insulation method, namely after concrete pouring molding, through insulation material or injection timing pouring hot water, storage hot water and other ways, improve the concrete surface and the surrounding the radiating surface temperature, from outside of the structure for temperature control. The basic principle of the insulation method is that the initial temperature of concrete is coupled with the temperature rise of cement hydration heat. In the slow cooling process (through man-made control), the concrete is obtained with the strength of the concrete..

In the concrete curing stage temperature control should follow the following points:

7.1. Between the concrete of center and surface temperature, concrete surface temperature and outdoor minimum temperature difference should be less than 20 DEG C; when the concrete structure has enough ability to crack, not more than 25 degrees to 30 degrees.

7.2. The concrete form removal of concrete, temperature does not exceed 20 DEG C. The temperature difference should include the temperature difference between the surface temperature, the central temperature and the outside temperature.

7.3. Internal cooling method to reduce the temperature difference between inside and outside of concrete. Internal cooling method is the internal water pipe in the concrete, through the cooling water, reduce the internal temperature of the concrete. Cooling in concrete pouring just finished began, and common investment and rubble method can effectively control the concrete cracks caused by the temperature difference inside and outside of the concrete.

7.4. Heat insulation method is in structures exposed concrete surface and the outside formwork covering heat preservation material (such as straw bags, sawing wood, wet sand etc.). In the slow cooling process, make the concrete to obtain the necessary strength and to control the concrete temperature difference between inner and outer of less than 20 DEG C.

7.5. The concrete surface crack laying steel mesh to produce dry to prevent the concrete shrinkage. In the mass concrete construction grasp its basic knowledge, and according to the actual take measures, will make the construction quality get good guarantee.

\section{REFERENCES}

[1] Large volume concrete construction specification [S] GB504962009

[2] Wang Tiemeng, engineering structure crack control [M] China Building Industry Press, 2002

[3] Yang Sixin, senior construction manual [M] China Building Industry Press 1992.

[4] Zhang Jianren. Problems and Countermeasures of large volume concrete. Shandong education, 2000, 9.

[5] Underground engineering waterproof technical specification [S] GB50108-2001. 